pressure technology that have made this progress possible, the text has been added to and modified considerably, so that this edition may be regarded as a new book on the subject.

The chief aim of the author was to provide a practical guide to the design of industrial high-pressure plant; although the work is mainly concerned with equipment used in the chemical industry, the general background of high-pressure technology is broadened by frequent references to the techniques used in the design of nuclear power plant. The practical nature of the book is emphasized by the inclusion of an introductory chapter devoted to the various codes of practice, specifications and statutory requirements for the design and operation of pressure plant. It is unfortunate that the references to British Standard 1500 on "fusion welded pressure vessels for the chemical and allied industries" which occur throughout the book concern the provisional code issued in 1949 and not the extensively revised edition published in 1958.

Although the pressure vessel codes give detailed practicel design procedures for vessels operating at pressures up to about 200 atmospheres, for higher pressures there are as yet no accepted codes and the chemical engineer must base his designs largely on first principles. It is with the principles governing the design, fabrication and choice of material of construction for highly stressed vessels that the first half of the book is concerned. The basic theory underlying the design of both monobloc and compound cylinders is supplemented by the detailed results of recent experimental work on the yield and rupture of thickwalled cylinders. In addition to the well-known methods of fabrication, such as hollow forging and fusion welding, the newer techniques of tape-winding and the multi-layer form of construction are described in detail. In view of the increasing use now being made of the autofrettage procedure for extending the elastic range and prolonging the fatigue life of thick-walled hollow cylinders, the chapter dealing with this subject is disappointing in that very little design information is given. The same criticism may also be made of the section concerned with the problems of creep at high temperatures; furthermore, no mention is made of the effect of fatigue on design. On the other hand, much useful information, not readily accessible in the literature, has been brought together in those sections of the book which deal with the low-temperature embrittlement of steels and with those corrosion problems peculiar to high-pressure plant.

The second part of tho book, which is mainly concerned with ancillary equipment such as pumps, compressors and valves, provides the reader with well-illustrated and detailed descriptions of a large number of designs. Since the requirements of industrial processes are so diverse, the author has had to exercise careful judgment in selecting suitable examples to demonstrate the salient features of the various items of plant. In addition, much useful information is given concerning the techniques employed in a number of continuous high-pressure catalytic processes and the methods used for the preparation and purification of industrial gases.

Unhappily the author died earlier this year, soon after the publication of this edition of his first book. In compiling it, he has performed a valuable service to all those interested in the field of high-pressure technology.

\section{ANNUAL REVIEW OF ENTOMOLOGY}

\section{Annual Review of Entomology}

Vol. 5. Edited by Edward A. Steinhaus and Ray F. Smith. Pp. vii +451. (Palo Alto, Calif.: Annual Reviews, Inc., 1960. Published in co-operation with the Entomological Society of America.) 7 dollars.

I HE aim of this "Annual Review" is to cover the whole science of entomology, pure and applied; and since the insects provide at least five-sixths of all known species of animals, are exceedingly diverse in form and function, have a tremendous influence on the economy and health of man, and are being studied by a very large army of investigators-there is no shortage of material for annual review. The study of some subjects has only recently begun. It is still possible for all work on the fine structure of insects to be summarized in a single article (G. A. Edwards). Cytogenetics of insects has been studied for many years and the review by S. G. Smith covers only selected highlights from the recent literature. A few years, ago a review dealing with the biochemistry or neurophysiology of insects would have been a rather unsophisticated affair, from sheer lack of knowledge. But that is no longer so ; the article on insect flight muscles and their physiology (E. G. Boettiger) shows that in both these fields new basic ideas are being worked out on insects. In thэ physiology of neurosecretion, which is well reviewed by W. G. Van de Kloot the insects have always led the way.

The editors of the "Annual Reviews" maintain a constant effort to persuade their authors to present a point of view and not just an annotated catalogue of references. They score a fair proportion of successes with their entomologists. In writing on host selection in phytophagous insects A. J. Thorsteinson contests the assumption made in an earlier review by Fraenkel and Lippe that only the adventitious flavours of plants are utilized in host selection, never the nutrients themselves. But if a point of view is put too strongly a review can degenerate into a polemic. In surveying once more the question of population control, H. G. Andrewartha and L. C. Birch make a serious effort to get away from the sterile theoretical arguments about density-dependent factors and to discuss some actual contributions to the study of insect abundance in Nature. Mecnanisms of resistance are again reviewed, this time by A. W. A. Brown, who quotes 229 references; a number exceeded only by L. R. Jeppson and G. E. Parman, writing on insects and mites as pests of citrus, who have 240 . That represents about half of the twenty articles in this volume. The range of subjects covered is so wide that every year there is plenty of material to choose from which really needs reviewing. The high standard of earlier volumes is maintained this year.

The print in these volumos is rather small, which reduces the impact of their content on the reader ; but it is pleasant not to have them printed on the highly sized paper so much favoured in the United States. However, a substantial number of pages in the copy received for review showed the letterpress on the other side of the page so clearly as to be difficult to read.
V. B. WIGGLesWORTH 